\title{
The Dermal Sinus: About 29 Cases and Review of the Literature
}

\author{
F. Bouchenaki ${ }^{1 *}$, N. Habchi ${ }^{2}$, M. Bouallag ${ }^{2}$, K. Boustil1, M S. Benachour ${ }^{1}$, S. Bakhti1n. Ioualalen ${ }^{2}$, M.djaafer ${ }^{1}$ \\ ${ }^{1}$ Neurosurgery Department ALI AIT IDIR Hospital Health Establishment, Algiers, Algeria \\ ${ }^{2}$ Neurosurgery Department, MUSTAPHA PACHA University Hospital, Algiers, Algeria
}

*Corresponding Author: F. Bouchenaki, Neurosurgery Department ALI AIT IDIR Hospital Health Establishment, Algiers.

Received date: December 10, 2021; Accepted date: December 27, 2021; Published date: January 03, 2022

Citation: F. Bouchenaki, N. Habchi, M. Bouallag, K. Boustil, M S. Benachour, S. Bakhti1n. Ioualalen, M.djaafer et all. (2022). The Dermal Sinus: About 29 Cases and Review of the Literature. J. Neuroscience and Neurological Surgery. 11(2); DOI:10.31579/2578-8868/226

Copyrights: (c) 2022 F. Bouchenaki, This is an open-access article distributed under the terms of The Creative Commons Attribution License, which permits unrestricted use, distribution, and reproduction in any medium, provided the original author and source are credited

\begin{abstract}
The term spina includes several types of congenital malformations including closed spinal dysraphisms, among these $10 \%$ are dermal sinuses.

Our series includes 29 patients, the majority of which were asymptomatic, but these can present with different clinical pictures including neurological and / or infectious signs indicating a neglected dermal sinus and which therefore requires urgent treatment in the environment. Neurosurgical.

MRI confirmed the diagnosis showing the dermal sinus tract communicating from the surface of the skin to the intra-dural space.

Once the diagnosis has been made, surgical treatment becomes imperative and urgent because, despite the benignity of the lesion, the majority of which are located in the lumbar region, can lead to formidable neurological sequelae compromising the functional prognosis or even the vital prognosis in some cases.

All of our patients were operated on and we obtained $90 \%$ good results, however we deplore one case of aggravation and one death.
\end{abstract}

Key words: dermal sinus; dysraphism; cutaneous stigmata and complications

\section{Introduction}

Dermal sinus is a rare dysraphism that occurs in approximately one in 25,000 births [1-2-3].

It is the result of incomplete obliteration of the dermal elements during the closure of the neural tube during embryonic development.

They represent $10 \%$ of firm spina according to the literature review, the lumbar location is the most frequent [4-2-5].

Clinically, the dermal sinus can manifest itself in different forms ranging from the asymptomatic form, especially in newborns or infants, to that including neurological signs associated or not with infectious signs, which is seen in older children.

MRI was performed in all of our patients, which confirmed the diagnosis and revealed associated lesions which can be various such as attached lower marrow, dermoid and epidermoid cysts; or abscesses of the ponytail.

Despite the mildness of the lesion, the diagnosis must be made in order to avoid the installation of complications that put the functional prognosis into play, leaving definitive neurological sequelae and sometimes lifethreatening.

\section{Patients and Methods}

This is a retrospective study where we identified 29 patients during a period from January 2014 to July 2020

The sex ratio was 16 boys and 13 women.

The age varies between 1 month and 15 years which are broken down as follows: 11 patients whose age is less than 1 year; 9 patients between one and four year's old and 6 patients over four years old. Table 1

\begin{tabular}{|l|l|l|}
\hline Age & \multicolumn{2}{|l|}{ Number of patients } \\
\hline < 1 year & 11 & $37.93 \%$ \\
\hline 1 year - 4 years & 9 & $31.03 \%$ \\
\hline 4 years - 8 years & 6 & $20.68 \%$ \\
\hline 8 years - 12 years & 2 & $6.89 \%$ \\
\hline 12 years - 15 years & 1 & $3.4 \%$ \\
\hline
\end{tabular}

Table 1: breakdown by age 
The lumbar seat being the most frequent 26 cases $(89.65 \%)$ followed by 2 in the dorsal region and one case in the cervical region.

Clinically, the majority of our patients were asymptomatic in 22 patients $(75.86 \%)$.

4 patients $21 \%$ presented with recurrent signs of meningitis, one of which was complicated by the sudden onset of acute paraplegia.

Motor disorders are present in 09 cases (31.03\%) with a type of peripheral type deficit involving one or more radicular territories concerning one or both lower limbs which may be accompanied by amyotrophy.

In addition, 7 patients $(24.13 \%)$ present sphincter disorders such as urinary incontinence and demonstrated by ultrasounds which show an impact on the urinary system

Transit disorders such as obstinate constipation isolated or accompanying urinary disorders in 04 cases. Table 2

\begin{tabular}{|l|l|l|}
\hline Neurological signs & Number of cases & Percentage \\
\hline Skin stigmata & 29 cases & $\mathbf{1 0 0 \%}$ \\
\hline Sciatica & $\mathbf{0 2}$ cases & $\mathbf{6 . 9 0 \%}$ \\
\hline Acute paraplegia & 01cases & $\mathbf{3 . 4 4 \%}$ \\
\hline Deficiency of I.M & 07 cases & $\mathbf{2 4 . 1 3 \%}$ \\
\hline Urinary incontinence & $\mathbf{0 7}$ cases & $\mathbf{2 4 . 1 3 \%}$ \\
\hline Chronic constipation & $\mathbf{0 4}$ cases & $\mathbf{2 4 . 1 3 \%}$ \\
\hline Recurrent meningitis & $\mathbf{0 2}$ cases & $\mathbf{6 . 9 0 \%}$ \\
\hline Normal exam & $\mathbf{2 2}$ cases & $\mathbf{7 5 . 8 6 \%}$ \\
\hline
\end{tabular}

Table 2: Clinical manifestation

-The orthopedic manifestations of scoliosis and equinovarus feet are only present in 04 cases (13.79\%).

-Skin stigmata are present in all our patients (100\%); sinus ostium associated with a skin pigmentation disorder that may go unnoticed, or has hypertrichosis may be seen.

Hypertrichosis with dermal sinus

Punctiform dermal sinus

Cutaneous angioma

Infected dermal sinus

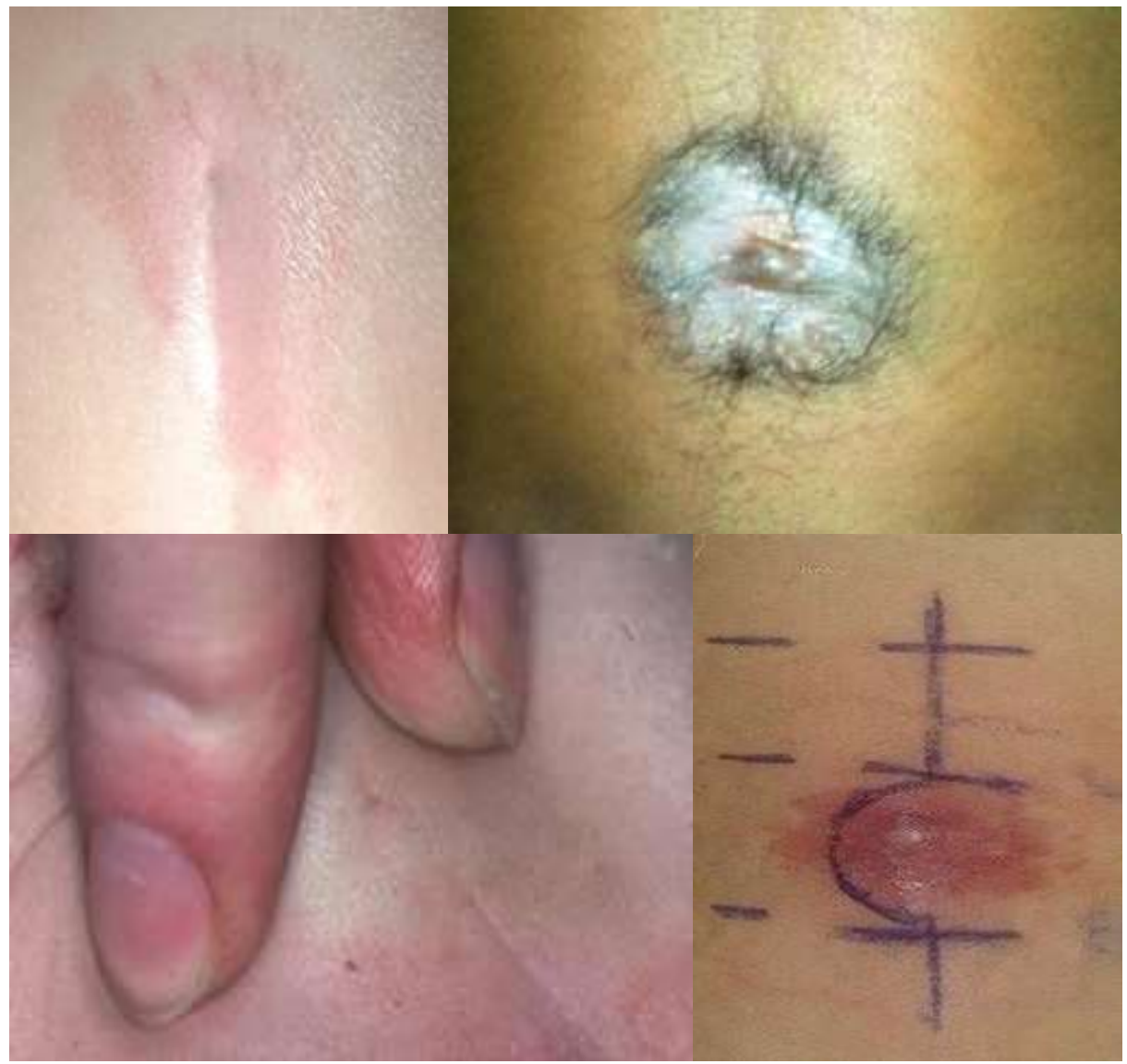


-MRI is the examination of choice and performed in all cases, which has made it possible to highlight the direction and depth of the tract; and any associated lesions [4-6]
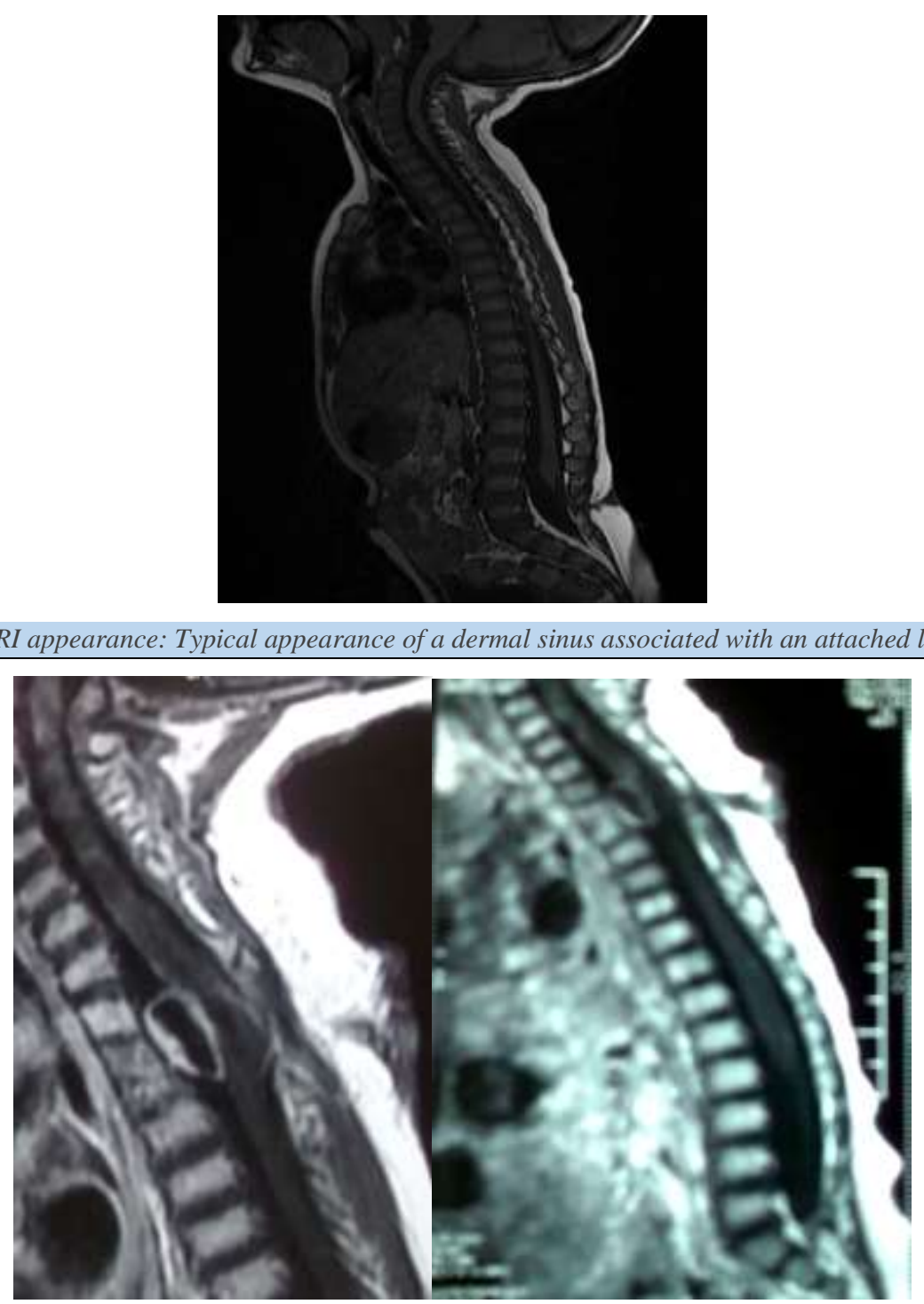

Figure 3: cervical dermal sinus complicated by an abscess

The surgical treatment will consist of a laminectomy the aim of the surgery was to completely excise the sinus tract and treat the associated lesions in one step

Surgery was performed in all cases through a midline incision bypassing the sinus.

The sinus tract was followed through the subcutaneous tissue and muscle layer to its end and completely excised.
After performing the laminectomy, the dura was opened; In cases where the sinus tract was intradural, part of the dura surrounding it was excised.

The intraspinal pathologies were treated accordingly, the dermoid cyst and epidermoid were removed; drainage of the abscess, removal of arachnoid adhesions in arachnoiditis and release of the marrow were done in the case of a marrow attached by a thick filum.

Patients with infectious complications were managed with appropriate antibiotics according to the results of the antibiogram. 


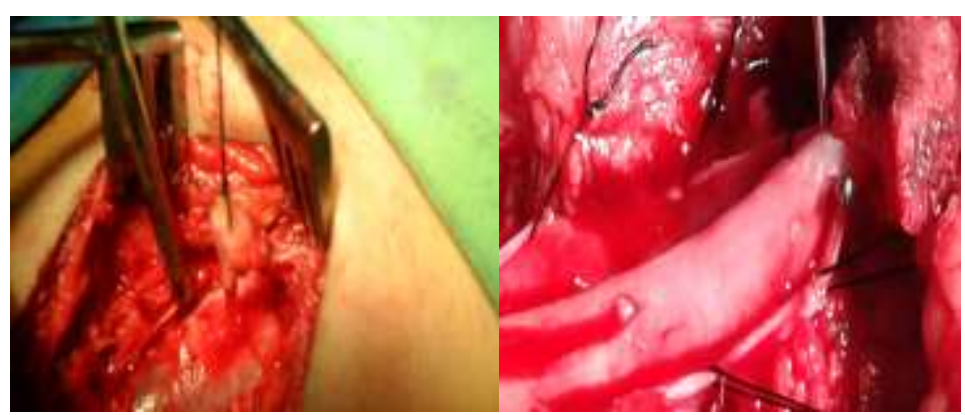

Figure. 4: Peroperative appearance of a dermal sinus and its tract and root arachnoiditis

\section{Discussion}

The dermal sinus is a lesion belonging to the closed spina; which represents $10 \%$ of closed spina according to the literature review

It is the result of the incomplete disjunction between the neuroectoderm and the cutaneous ectoderm its depth can vary from the fascia to the spinal cord, this tract lengthens during growth due to the ascent and can cross several levels in the epidural space before entering the subarachnoid spaces.

According to the literature review $60 \%$ of the dermal sinuses penetrate into the subarachnoid spaces and $27 \%$ are attached to such cauda equina roots and / or to the filum terminale [1-7-8-9].

It can also end in extra-dural space in $10 \%$ to $20 \%$ of cases [4-8].

The lumbar seat is the most frequent it varies from 40 to $70 \%$ according to the literature review in our series it is estimated at $89 \%$ of cases.

The dermal sinus must be differentiated from the sacrococcygeal fossa by the fact that they are located above the intergluteal cleft and have a cephalic orientation and associated with other pathologies while the dimples are blind and located in the slit to the tip of the coccyx.

They are caudally oriented unlike the dermal sinus and are not associated with other intradural manifestations [6-10-11].

22 of our patients $(75.86 \%)$ were asymptomatic like that of the METE series [3] which shows that patients under one year old are more likely to be neurologically asymptomatic than older children, because beyond this age group there is a risk that it presents neurological signs related to the development of associated pathologies such as tumors:

-The presence of dermoid and epidermoid tumors, which is estimated to be between 83 and $13 \%$ respectively [7], was only found in our series in 9 patients, ie $31 \%$.

- The attached lower marrow is also the most frequent nerve lesion in our series, $66 \%$ of cases, while the literature review estimates it to be between 40 and $55 \%$ of cases [6].

-Infection of the central nervous system by the presence of 4 cases of abscess $(13.79 \%)$ in the lumbar region following recurrent and complicated meningitis. Table 3

\begin{tabular}{|l|l|l|}
\hline \multirow{2}{*}{ Associated nerve damage } & Per operative aspect \\
\cline { 2 - 3 } & literature & Our serie \\
\hline Epidermoid cyst & $13 \%$ & 3 cases $10.3 \%$ \\
\hline Dermoid cyst & $83 \%$ & 6 cases $20.68 \%$ \\
\hline Low marrow attached & $22-40 \%$ & 12 cases $66.6 \%$ \\
\hline Diastematomyelia & $23.8 \%$ & - \\
\hline Lipomyelomeningocele & $4.76 \%$ & - \\
\hline Syringomyelia & $9.5 \%$ & \multicolumn{2}{|c|}{3 cases $10.3 \%$} \\
\hline Abscess & $19 \%$ & 4 cases $13.79 \%$ \\
\hline
\end{tabular}

Table 3: Lesions associated with the dermal sinus

Regarding the results, not all of our asymptomatic patients worsened $(100 \%)$. With regard to symptomatic patients (07 cases or $24.13 \%$ ): improvement in motor deficits and sphincter disorders was seen in only 05 cases $(71.42 \%)$; among these 2 patients who presented recurrent episodes of meningitis in the history which could be explained by the rapid management given the sudden onset of a deficit in less than 72 hours

The 2 patients who did not recover and therefore remained at the same neurological stage 01 case as on admission despite our intervention did not register any motor improvement or sphincteric are those who have presented recurrent meningitis on several occasions and whose diagnosis was not made until late and or were grafted with neurological deficits 01 case whose recovery was very difficult if not impossible; as there was severe arachnoiditis lesions of the roots of the cauda equina which was complicated by meningoencephalitis resulting in the death of the patient. Table 4 


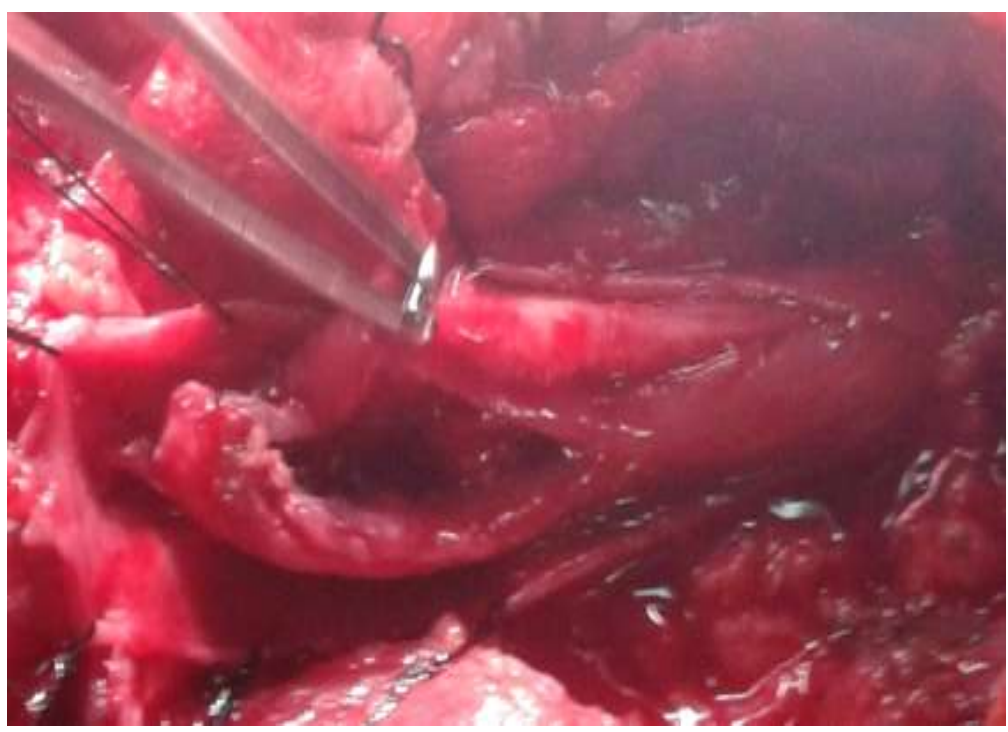

Figure 5: Appearance of severe arachnoiditis of the roots of the ponytail

\begin{tabular}{|c|c|c|c|c|c|}
\hline & Ackerman & Jindal & Ramnarayan & Mete & Our serie \\
\hline Number of patients & 28 & 26 & 9 & 16 & 29 \\
\hline Asymptomatic & $39 \%$ & $13 \%$ & $111.11 \%$ & $75 \%$ & $22 \quad 75.86 \%$ \\
\hline Improved & $43 \%$ & $34.7 \%$ & $444.4 \%$ & - & $5 \quad 11.11 \%$ \\
\hline Stabilized & $7 \%$ & $14 \quad 60.8 \%$ & $444.4 \%$ & $25 \%$ & $11.11 \%$ \\
\hline Worsening & $11 \%$ & $4.3 \%$ & & - & $05.55 \%$ \\
\hline
\end{tabular}

Table 4: Results and comparison according to the literature review

\section{Conclusion}

The dermal sinus is a closed spinal dysraphism which is benign in appearance but which can be responsible for debilitating and definitive neurological sequelae in a young patient in the event of neglected dermal sinus; to think about it in front of any recurrent meningitis whether it is septic or not by a careful clinical examination for skin stigmata and to carry out the necessary investigations in order to confirm or not the diagnosis because prophylactic surgery of the dermal sinus is an emergency and not a chimera.

\section{Références}

1. Ackerman LL, Menezes AH, Follett KA. Cervical and thoracic dermal sinus tracts. A case series and review of the literature. Pediatr Neurosurg. 2002;37:137-147. [PubMed]

2. Kaufman BA. Neural tube defects. Pediatr Clin North Am. 2004;51:389-419. [PubMed]

3. Mete M, Umur AS, Duransoy YK, Barutçuoglu M, Umur N, Gurgen SG, et al. Congenital dermal sinus tract of the spine: Experience of 16 patients. J Child Neurol. 2014;29:1277-1282. [PubMed]

4. Jindal A, Mahapatra AK. Spinal congenital dermal sinus: An experience of 23 cases over 7 years. Neurol India. 2001;49:243246. [PubMed]
5. Martínez-Lage JF, Pérez-Espejo MA, Tortosa JG, Ros de San Pedro J, Ruiz-Espejo AM. Hydrocephalus in intraspinal dermoids and dermal sinuses: The spectrum of an uncommon association in children. Childs Nerv Syst. 2006;22:698-703. [PubMed]

6. Ackerman LL, Menezes AH. Spinal congenital dermal sinuses: A 30-year experience. Pediatrics. 2003;112:641-647. [PubMed]

7. Gupta DK, Shastank RR, Mahapatra AK. An unusual presentation of lumbosacral dermal sinus with CSF leak and meningitis. A case report and review of the literature. Pediatr Neurosurg. 2005;41:98-101. [PubMed]

8. Radmanesh F, Nejat F, El Khashab M. Dermal sinus tract of the spine. Childs Nerv Syst. 2010;26:349-357. [PubMed]

9. Tubbs RS, Frykman PK, Harmon CM, Oakes WJ, Wellons JC., 3rd An unusual sequelae of an infected persistent dermal sinus tract. Childs Nerv Syst. 2007;23:569-571. [PubMed]

10. Elton S, Oakes WJ. Dermal sinus tracts of the spine. Neurosurg Focus. 2001;10:e4. [PubMed]

11. Pang D, Dias MS, Ahab-Barmada M. Split cord malformation: Part I: A unified theory of embryogenesis for double spinal cord malformations. Neurosurgery. 1992;31:451-480. [PubMed]

12. Spinal dorsal dermal sinus tract: An experience of 21 cases Ishwar Singh,Seema Rohilla, Prashant Kumar, Saurabh Sharm Surg Neurol Int. 2015; 6(Suppl 17): S429-S434. 


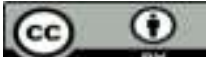

This work is licensed under Creative Commons Attribution 4.0 License

To Submit Your Article Click Here: Submit Manuscript

DOI: $10.31579 / 2578-8868 / 226$
Ready to submit your research? Choose Auctores and benefit from:

$>$ fast, convenient online submission

$>$ rigorous peer review by experienced research in your field

$>$ rapid publication on acceptance

$>$ authors retain copyrights

$>$ unique DOI for all articles

$>$ immediate, unrestricted online access

At Auctores, research is always in progress.

Learn more https://auctoresonline.org/journals/neuroscience-and-neurologicalsurgery 